\title{
APPENDIX
}

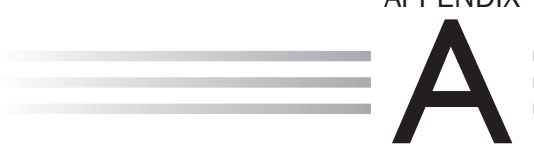

\section{Healthy People 2020 Topics}

A

Access to Health Services

Adolescent Health (New)

Arthritis, Osteoporosis, and

Chronic Back Conditions

B

Blood Disorders and Blood Safety (New)

C

Cancer

Chronic Kidney Disease

D

Dementias, Including Alzheimer's Disease (New)

Diabetes

Disability and Health
E

Early and Middle Childhood (New)

Educational and Community-

Based Programs

Environmental Health

F

Family Planning Food Safety

G

Genomics (New)

Global Health (New)

$\mathrm{H}$

Health Communication and Health Information Technology 
Healthcare-Associated Infections (New)

Health-Related Quality of Life and Well-Being (New)

Hearing and Other Sensory or Communication Disorders Heart Disease and Stroke HIV

I

Immunization and Infectious

Diseases

Injury and Violence Prevention

$\mathrm{L}$

Lesbian, Gay, Bisexual, and Transgender Health (New)

\section{M}

Maternal, Infant, and Child Health

Medical Product Safety

Mental Health and Mental

Disorders

$N$

Nutrition and Weight Status

Adapted from Healthy People 2020. (n.d.). Topics and ObjectivesObjectives A-Z. U.S. Department of Health and Human Services. Retrieved August 10, 2014 from www.healthypeople.gov/2020/ topicsobjectives2020/

Physical Activity

Preparedness (New)

Public Health Infrastructure

$\mathrm{R}$

Respiratory Diseases

S

Sexually Transmitted Diseases Sleep Health (New)

Social Determinants of Health (New)

Substance Abuse

$\mathrm{T}$

Tobacco Use

$\mathrm{V}$

Vision

Occupational Safety and Health Older Adults (New)

Oral Health

P 